\title{
An Informetric analysis of publication and research collaboration patterns in natural and applied sciences in South Africa
}

\author{
Daisy Jacobs ' \\ Department of Library and Information Science, University of Zululand, South Africa \\ djacobs@pan.uzulu.ac.za
}

\begin{abstract}
Recieved : $4^{\text {th }}$ September 2007
Accepted : 12th October 2007

This study is the part of an ongoing research which presents the mainstream scientific output and collaboration of five research universities of South Africa over a 9 year period between 1995 and 2003. Since a part of this research has already been published in 2006 where the main emphasis was on publication output, this paper concentrates more on collaboration. The paper discusses the distribution of publications by institutions, index of specialization, collaboration and patterns of co-authorship. The results show that South African authors collaborated more frequently with international authors $(73.99 \%)$ than with national authors $(26.01 \%)$. This was confirmed statistically at a confidence level of $p$-value $<0.025$. A further non-parametric chi-square statistical analysis illustrated that there are significant differences in the proportion of co-authorship amongst the five institutions ( $p$-value $<0.005)$. The results obtained shows that there is a sharp decline in publication output from 1995 until the end of 1998 and then again from 2003. The decrease in publication output is also an indication of the lack of collaborative research by South African scientists.
\end{abstract}

Key Words: Informetrics; Research Collaboration; Natural and Applied Sciences; South Africa

\section{Introduction}

A primary feature of modern science is that researchers collaborate in teams. Research teams appeared sporadically already during the $19^{\text {th }}$ century (Havemann, 200 I), and are now so common that on various occasions scholars in science studies have stipulated using teams as basic units of investigation as opposed to individual researchers. Very often, in many fields, researchers without teams cannot keep up with developments on the research front.

According to Haiyan, Hildrun and Zeyuan (2004), there have been varying manifestations of collaborative work. And since the pioneering work of Price (1963), and Beaver and Rosen (1978, 1979, 1979), a large number of scholars have stressed different forms and roles of scientific collaboration in different scientific fields. An investigation into these researchers can be made by analysis at micro level (individuals), meso level (institutions), or macro level (countries) (Glanzel 2002, Kretschmer 2004).

The last few decades have witnessed a restructuring in scientific research where the pattern of scientists working alone gradually giving way to collaborating with colleagues from the same institution or from other institutions. In this way, it has increasingly become a collaborative endeavour (Subramanyam 1983). There is also a strong trend towards borrowing from, and interpenetration across disciplines. As a result of these trends, there is a rise in collaboration both within interdisciplinary research and an increasing interest in collaboration amongst both researchers and science policy makers. The global tendency towards more collaboration in scientific research - often crossing the borders of institutes and countries - has been demonstrated in many scientific fields (Havemann, $200 \mathrm{la}$ ). For researchers to work together in order to solve problems is so common now in many branches of science and technology, that in many cases it makes more sense to consider groups as the basic units of research rather than individual scientists (Seglen and Aksenes, 2000). To establish and maintain collaboratiive links can be more or less easy - depending on the scientific, cultural, political, and geographical barriers that must be overcome. Havemann (200I) is of the opinion that in recent years, some of these barriers have been lowered, especially in transnational collaboration.

How research collaboration and productivity are correlated has been studied by many scholars. A recent study by Seglen and Aksnes (2000) delves in to scientific productivity and group size and the result of the study carried out by Gupta and Karisiddapa (1998) shows that there has been a systematic increase over time in the number of papers per author in the subset of collaborative researchers.

There were three comprehensive bibliometric studies carried out by Jacobs and Ingwersen(2000); Ingwersen and Jacobs (2003); and Jacobs (2006) which measured the trend in publication of South African scientists. First of these studies carried out a research on the development and research of scientists for a sixteen year period starting from 198I-1996. The five standard fields chosen were animal and plant sciences, and veterinary medicine. In the second study, where the period of study extended from 198I-2000, the authors used plant and animal science, chemistry, physics, general and

I. Daisy Jacobs, PhD, is Senior Lecturer in the Department of Library and Information Science, University of Zululand, South Africa. 
internal medicine and the stress was on the citation impact. They compared South African research with New Zealand and Mexico and compared the publication volume with world shares. The study investigated the productivity of scientists for the entire period 1981-2000 and brought out the strengths and weaknesses of different areas of science in the country. The study also came to the conclusion that the citation impact of the sciences only started picking up after 1994 after the embargo on the country had been lifted.

Purpose

The present study has investigated the position of South Africa in relation to collaboration both inter-institutional and international. International scientific collaboration has generated increased interest in recent years due to the higher quality of collaborative papers as shown by higher average impacts compared to solely national publications (Van Raan, 1998) and the benefit gained by peripheral countries from international collaboration which integrates their national publications in the international scientific network (Russell, 1995).

The purpose of this paper was to explore mainstream scientific research and collaboration of the authors both nationally and internationally as well as to illustrate the extent of scientific development in South Africa. Although there has been extensive studies on collaboration in other countries no such comprehensive studies have been carried out in South Africa, hence this study.

- To identify the main South African institutions that are actively involved in the production of the main disciplinary fields

- To investigate the growth and development of South African scientific publications, 1995-2003 among the selected universities

- To examine the extent of production in the seven selected fields such as physical sciences, plant and animal sciences, engineering and clinical medicine.

- To determine the extent of international collaboration among the faculties of these five institutions.

- To study the specialization index for selected fields using publication data for the given period

\section{Methodology}

The data for study has been collected from CD-ROM and Web versions of the Science Citation Index (SCI) and social Sciences citation Index (SSCl) which is published by the Institute of Scientific Information (ISI), presently the Thomson Scientific. All papers were recorded in the annual volumes of the Science Citation Index (SCI) of the Institute for Scientific Information (ISI) for the period of 1995-2003. The data for each document included author names, title, abstract, date, document type, and cited references. Author names were standardised as some authors may report their names differently in different papers. Each author was identified by his/her surname and first initial only (Newman, 200I).

The following five research institutions of South Africa were selected for the study. They were the Universities of Pretoria (UP), Cape Town (UCT), Natal ${ }^{2}$ (NATAL), Stellenbosch (STELL) and Witwatersrand (WITS). The five institutions were considered as the research universities of the country as they seem to produce the bulk of scientific publication. This was proved by a research done by the author in her doctoral research where all twenty one universities were included. The research output of the five selected universities were $51 \%$ of the total and all the other universities put together only produced about $49 \%$ of the output.

The 7 main disciplinary fields were identified as Clinical Medicine (CLIN), Plant \& Animal Science (PLT\&ANM), Biology \& Biochemistry (BIO\&BICH), Engineering (ENGN), Environment \& Ecology (ENV\&ECO), Chemistry (CHEM) and Physics (PHY).

The performance of the five institutions was judged and compared on the basis of the following qualitative and quantitative indicators, (a) size of scientific activity measured by volume of production during the period of study (b) each institution's fields of specializations using the specialization index(SI) formula (c) and the collaboration of scientific activity measured by co-authorship. Once retrieved, records were analyzed using Microsoft Excel in order to identify the production distribution through out the period of study, distribution of publications by fields and institutions, and distribution by type of document, in order to determine whether one institution is more or less active in a specific field in comparison to other institutions. The specialization index (SI) formula was used (Godin, Robitaille, \& Côté, 200I). It was calculated as the share $(\%)$ of publications of institution $X$ in field $Y$ divided by the share (\%) of publications of all the institutions in field $Y$.

The study was also analytical in nature, with the application of suitable statistical tools to strengthen the empirical validity. The computer software, SPSS was used for processing. A non-parametric chi-square test was applied in the analysis of the differences of co-authorship amongst institutions, and a t-test was used to the rate of co-authorship rate. A

2. University of Natal is now called "University of Kwazulu Natal" 
further ANOVA analysis was conducted to study whether or not there was significant inter-institutional variation in their total publication out put in the mainstream exists.

\section{Results and discussions}

The results are represented under items $3 . \mathrm{I}$ to 3.4 and in table one and figures I to 3 below.

\subsection{The disciplinary distribution of South African publications}

Using the information available in the address field of the articles, the number of articles produced from the most productive South African institutions was calculated. In this study, only articles from the 9 year period of 1995-2003 were included. 19399 articles were identified in total from 7 fields of study amongst the 5 institutions. An analysis of the total out put presented in Table I indicates that the University of Cape Town (UCT) accounts for the largest share of South African publications (26.80\%) followed by UP (19.84\%). The University of WITS and STELL are in the range of I8- I9\%. The University of Natal with a share of $16.28 \%$ accounts for the least of all the other institutions. A further statistical analysis was employed to indicate if there was a significant level of inter-institutional differences identified in the total out put of publications. However, the result of a statistical analysis at $p$-value $>0.10$ does not reveal significant interinstitutional variation in their total publication output.

Table I Distribution of publications according to subject field and institutions

\begin{tabular}{|c|c|c|c|c|c|c|c|c|}
\hline \multicolumn{9}{|c|}{ Field (participation \%) } \\
\hline Institution & CLNIC & PLT\&ANM & $\mathrm{BIO \& BICH}$ & ENGIN & ENV\&ECO & CHEM & $\mathrm{PHY}$ & Total* \\
\hline UP & $560(14.55)$ & $1436(37.31)$ & $101(2.62)$ & $44 I(I I .46)$ & $377(9.80)$ & $332(8.63)$ & $602(15.64)$ & $3849(19.84)$ \\
\hline UCT & $1732(33.32)$ & $873(16.79)$ & $431(8.30)$ & $67 I(12.91)$ & $54 I(10.4 I)$ & $4 I I(7.91)$ & $539(10.37)$ & $5198(26.80)$ \\
\hline NATAL & $947(29.98)$ & $714(22.60)$ & $84(2.66)$ & $319(10.10)$ & $275(8.70)$ & $324(10.26)$ & $496(15.70)$ & $3159(16.28)$ \\
\hline STELL & $970(26.5 I)$ & $642(17.55)$ & $161(4.40)$ & $75 I(20.52)$ & $321(8.77)$ & $309(8.44)$ & $505(\mid 3.80)$ & $3659(18.86)$ \\
\hline WITS & $1516(42.90)$ & $379(10.72)$ & $158(4.50)$ & $338(9.56)$ & $232(6.56)$ & $360(10.17)$ & $55 \mathrm{I}(15.60)$ & $3534(18.22)$ \\
\hline Total** & $5725(29.5 \mathrm{I})$ & $4044(20.85)$ & $935(4.82)$ & $2520(13.0)$ & $1746(9.00)$ & $1736(8.94)$ & $2693(13.88)$ & $19399(100)$ \\
\hline
\end{tabular}

In terms of disciplinary scientific publications for the period of study, out of the total of 19399,5725 or 29.5 I\% came from the field of Clinical Medicine, 4044(20.85\% from Plant and animal ( PLT\&ANM) science. BIO\&BICH counted for 935(4.82\%) and Physics, 2693 (13.88\%) and Engineering had a total of 2520 which was equivalent tol3.00\% respectively of the institutions' output for the period. The other disciplinary fields, in order of contribution, were ENV\&ECO 1746 (9.00\%), and CHEM, 1736 or (8.94\%). University of Pretoria had 560 publications out of the total output of 5725 publications by the five institutions in clinical medicine which was only $14.55 \%$ and was considered the lowest among the contributing institutions. However, notable differences were found with respect to the contribution made by individual institutions to different fields of study. The University of Pretoria, for example, had the highest percentage of contribution in PLT\&ANM science, I436 (37.31\%), PHY 602 (I5.64\%) and, the least was BIO\&BICH with only $102(2.62 \%)$ out of the total production. The University of WITS, on the other hand, has got the highest publication share in clinical medicine I5I6 (42.90\%) and the lowest in BIO\&BICH I 58 (4.50\%). The University of Cape Town and Natal were strong in the fields of Clinical medicine and PLT\&ANM science while the University of Stellenbosch showed its highest production in the fields of Clinical medicine $970(26.51 \%)$ and Engineering $75 \mathrm{I}(20.52 \%)$.

In general, coverage varies across different fields. The research and publications in Clinical medicine and, PLT\&ANM science were very encouraging. In Engineering and Physics, the coverage was somewhat lower. In the CHEM and ENV\&ECO the coverage tended to be poorer. The least contribution was from BIO\&BICH. These disciplinary differences have been proven using the appropriate statistical analysis and it was found that scientific publication differences amongst the seven fields of study were justified at a confidence level of $p<0.005$.

SA Jnl Libs \& Info Sci 2008, 74(I) 
3.2. South Africa's research institutions and their search activity

The graphing of article counts annually is an informometric technique that determines how many articles have been devoted to a given concept over time. The rationale for this method is that bibliographic records are a relatively objective indicator for measuring discourse popularity (Ponzi\& Michael 2003). Once information is published in the form of articles, annual counts can be captured to provide time-series data that can be charted and analysed. Based on the work of Abrahamson (199I, 1996) and Abrahamson \& Fairchild (1999), the bibliometric technique of article counting is a reliable analytical approach to begin an analysis of published literature in order to illuminate and trace the development of a concept.

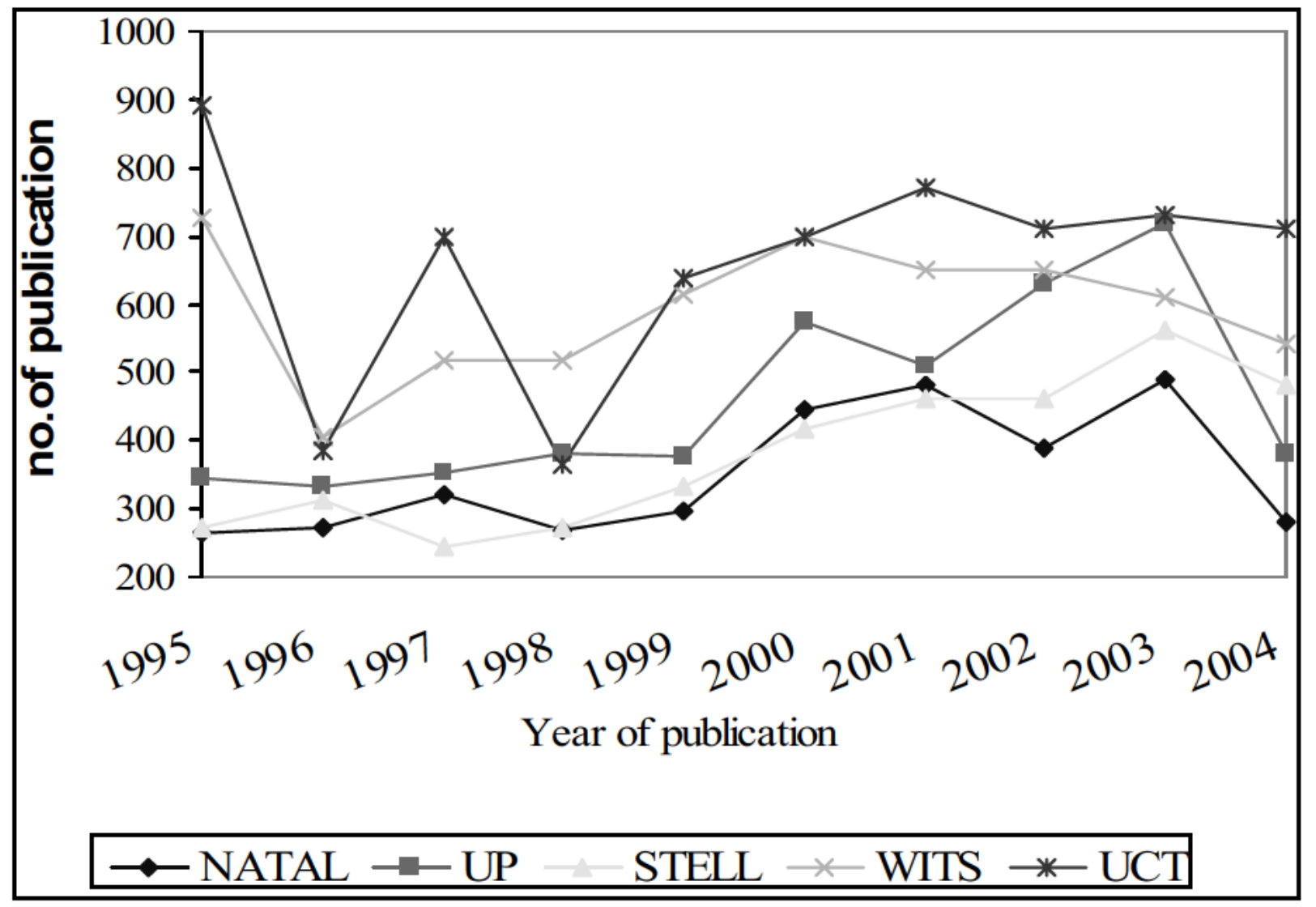

Figure 1 South Africa's institutional publication activity for 19952003

The percentage increases or decreases were calculated using 1995 as a base year. There was decreased productivity in the areas of science for all institutions during the period 1995 to 1999. Only universities of WITS and UCT showed an improvement in research during this period. Universities of Natal, UP and STELL showed a sudden rise in publication from the end of 1998 and this trend seemed to continue until 2003 with $84.10 \%, 108.10 \%$ and $105.10 \%$ respectively. The annual volume of UCT's scientific publications declined significantly in 1996 by $57.0 \%$ from 1995, and increased in 1997 to $81.80 \%$, after which it declined in 1998 to $59.20 \%$ (Figure I). After this year, however, the trend reversed. The number of publications was increased at a steady rate until $200 \mathrm{I}$ after which the rate of decrease continued.

Figure I displays a marked drop in production for all fields in 2003. The main reason for this is that the merges of universities and Technikons were being carried out and it is assumed that it had caused certain uncertainties in the area of science teaching and research, hence the drop in scientific research output.

The University of WITS showed a fairly steady increase in the number of scientific publications from 1996 to 2000, followed by relative stability until 2002. A decline began in 2003 (16.0\%) but it was less rapid than that of 1996 (44.10\%). In 2004, all the institutions' recorded output was lower than in 2003. The data available for 2004 is not complete, so it would be correct to state that the downward trend continued in that year as well. In general, the analysis of the institutional classification by year showed that there were two peaks in the distribution of research output first between 1999 to 2000 and the second from 2002 to 2003. 


\subsection{Index of specialization}

The absolute output of publication doesn't consider the size of the institution and discipline. The specialization index, therefore, makes it possible to determine whether an institution is more or less active in a specific field when compared to other institutions. A specialization index of an institution that is less than I means that the institution is not active in that field. In other words, it is less active in that field than the average of institution. If the index is higher than I, it would mean that the institution is more active in a given field than the average institution in the same field (Godin, Robitaille, \& Côté, 2001).

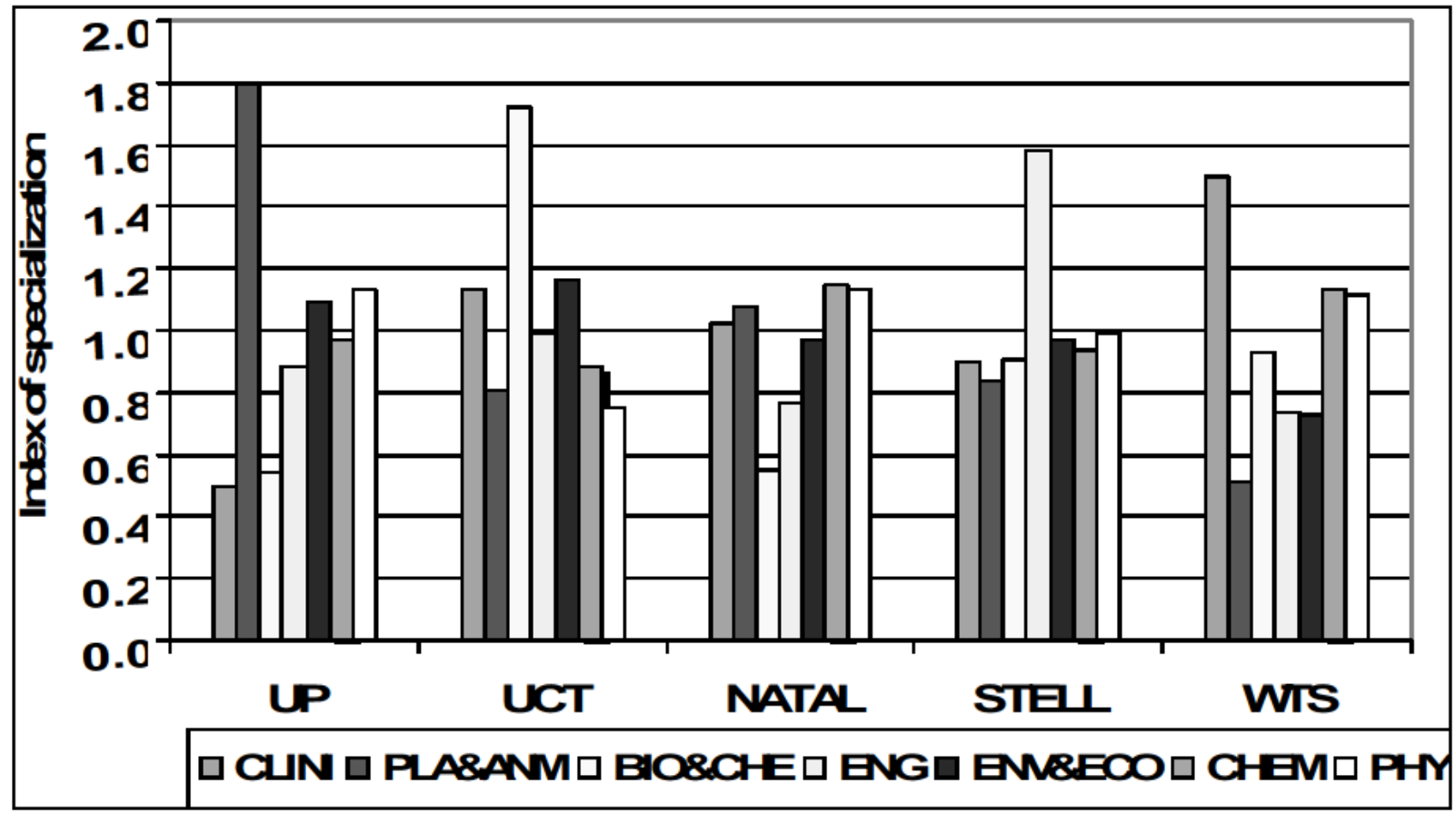

Figure 2 Index of Specialization (IS) for most productive institutions, 19952003

The specialization index, Figure 2, has been calculated for selected fields using publication data for the period 1995-2004. When interpreting the indicators one would take into consideration that the specialization of the different fields varies considerably. Generally, UP has a high relative publication activity in the PLT \& ANM science (SI I.80) and Physics (SI I.13). UCT, on the other hand, is more active in Clinical Medicine (SI I.I3), BIO\&BIOCHEM (SI I.72) and ENV\&ECO (SI I.16). The Universities of Natal and WITS have been very active in three disciplines Clinical Medicine, Chemistry and Physics. The analysis, moreover, shows that the field of Engineering is only active in research in STELL (SI 1.58). Similarly, UCT is the only institution that has performed well in BIO\&BIOCHEM (I.72).

\subsection{Scientific collaboration}

The globalization of science has resulted, among other things, in a generalized increase in international scientific collaboration, thus making necessary updated information on scientific co-operation, co-authorship, and influence. This is important not only for scientifically advanced countries but, perhaps, even more so for the developing world whose contribution to scientific achievement and its legacy does not receive the same level of attention and reflection (Berthelemot, Russell, Arvanitis, Waast \& Gaillard, 200I). There has been a significant increase in the number of internationally co-authored papers in many countries as well as in South Africa.

An analysis of the data of collaborations, Figure 3, shows that the share of national co-authorship is about $26.01 \%$, which is smaller than international collaborations (73.99\%). This is the general data collected. As the research advances, the author plans to do detailed analysis of research collaboration between institutions within the country as well as international collaboration. In terms of international collaboration, South African authors' collaboration with the USA and UK ranked first and second, with $45 \%$ and $13 \%$ respectively, in the period of 1994-2003. Other countries in order of ranking, were: France (8.05\%), Germany (7.80\%), Netherlands (7.60\%), Australia (3.40\%) and Belgium (3.20\%). However, the affiliation with other countries was very minute; such as Sweden (2.90\%), Japan (2.70\%), Canada (2.50\%) and with all the African countries as a whole (3.20\%). 
A further analysis of institutional collaboration patterns showed that all institutional researchers, except UP scientists, collaborate comprehensively with international authors. The share of international collaboration by percentage amongst institutions was as follows: STELL (9I.25\%), UCT (83.33\%), WITS (78.22\%) and Natal (68.84\%), while the corresponding share in UP was $44.87 \%$.

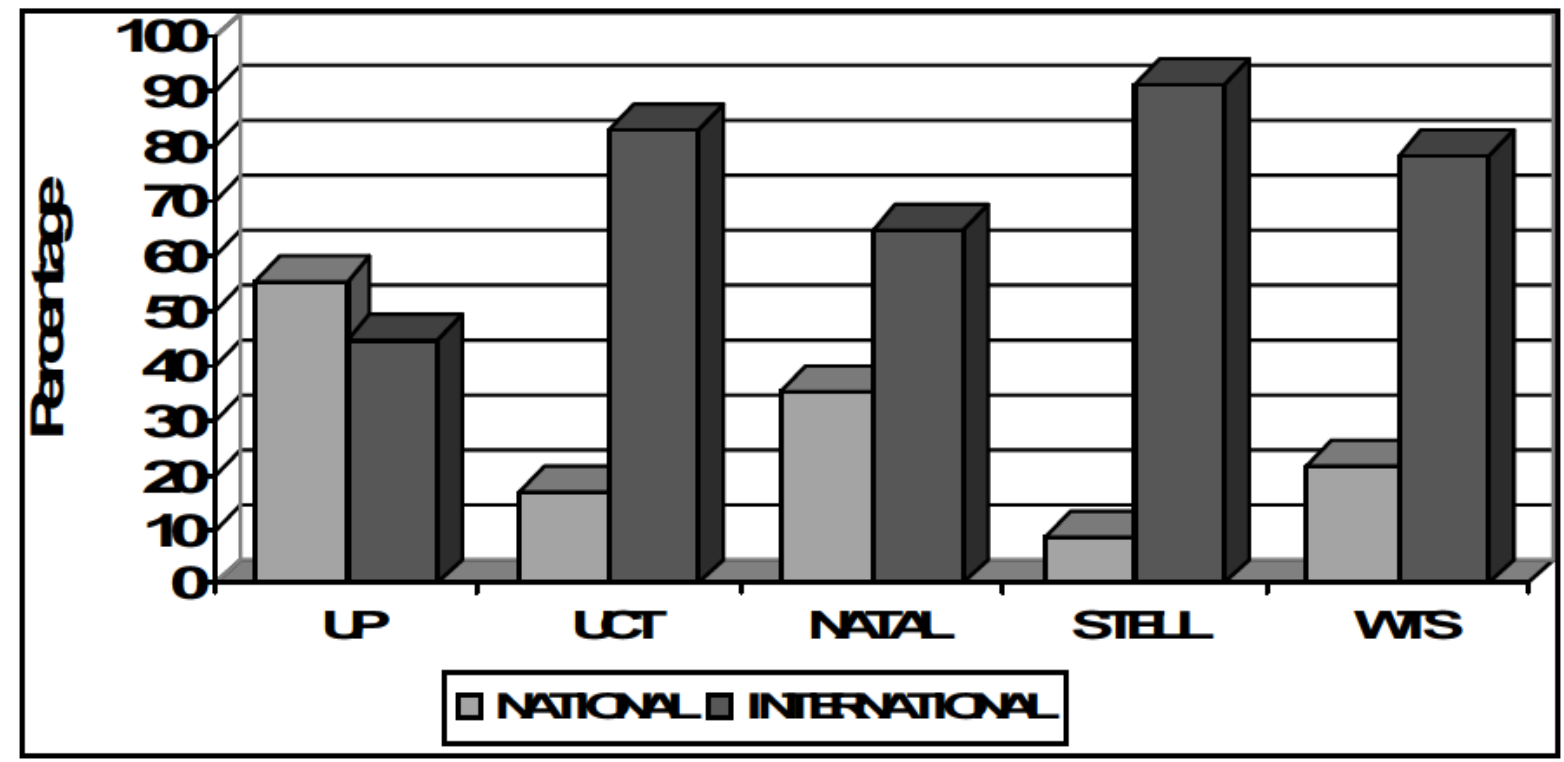

Figure 3 Scientific collaboration pattems in South Africa

A t-test was used to determine if there was a statistical significant difference between the means of national and international collaborations. The resulting $\mathrm{P}$-value of 0.0185 (P-value $<0.025$ ) indicates that South African authors collaborate more frequently with international scientists than they do with national, with the exception of UP scientists

The rate of international collaborations amongst institutions, Figure 3, illustrates that the Universities of STELL, UCT, and WTS came first, second and third respectively. This means that the authors from these institutions collaborate more internationally than nationally. On the other hand, the fact that the University of Pretoria achieved the lowest rate implies that the pattern of collaboration between national and international authors is somewhat the same. A further nonparametric chi-square statistical analysis was conducted to determine if there are significant differences in the proportion of co-authorship amongst the 5 institutions. The result ( $p$-value $<0.005)$, shows that there are significant differences in the rate of collaborations amongst the institutions.

\section{Conclusion and Recommendations}

This study has demonstrated that South African research in some of the institutions posed problems concerning article production which shows the failure in collaborative research as well. The research results of Ingwersen and Jacobs (2004) also showed that although several of the research fields are making progress but are vulnerable due to the small volume of publications. A concerted effort in collaborative research both nationally and internationally can rectify the failing situation in publication output. As in previous studies by Jacobs \& Ingwersen(2000); Ingwersen and Jacobs (2004), of the five standard field under analysis, Animal and plant sciences have done well only in certain institutions as well as Clinical medicine. If all the five research institutions selected had given priority to research to all the different disciplines, the kind of dip in output could have been avoided.

The purpose of the article was to identify the research and collaboration activities of the research institutions of higher learning in South Africa. The primary goals of research and collaboration were described, although in a limited way. When the planned research is completed, the author would be able to describe the extent to which research results are obtained and collaboration trend of institutions and the actual institutions and countries which are active participants in the collaborative research in South Africa. The results so far obtained showed that there were a total of 19399 articles from 7 fields of study amongst the five institutions during 1995-2003. Of these, the University of Cape Town (UCT) accounted for the largest share of South African publications (26.80\%) followed by UP (19.84\%). The University of WITS and STELL had a publication share in the range of $18-19 \%$. The University of Natal, with $16.28 \%$ share accounts for the least number of publications. While the growth of publications in each institution reveals important differences, a gradual increase in total article production was apparent. 
According to the results obtained in Jacobs (2006), the relative strengths and weaknesses of different institutions were demonstrated. University of Pretoria which showed a lead in research during the 1990s, started to decline slowly and University of Cape Town took the lead from the latter part of the 90s and managed to keep up the lead until 2003.

Most South African scientific publications came from the field of Clinical Medicine (29.5 I\%). PLT\&ANM science, PHY and ENGIN followed with $20.85 \%, 13.88 \%$ and $13.00 \%$ respectively. The other disciplinary fields, in order of percentage contribution, were ENV\&ECO (9.00\%), CHEM (8.94\%), and BIO\&BICH (4.82\%). Field of specialization varies greatly among institutions. UP, UCT and Natal have a higher relative publication activity in Plant \& Animal science (SI I.80), BIO\&BICH (SI I.72) and CHEM (SI I.I5) respectively. Whereas, STELL and WITS are more active in ENGIN (IS I.58) and CLNIC (IS I.50) respectively.

South African authors collaborated more frequently with international authors (73.99\%) than with national (26.01\%) authors even though the rate of institutional affiliation varies considerably. The international collaborations were highest with the USA (45\%) and the UK (13\%) and with other countries in the order of France $(8.05 \%)$, Germany $(7.80 \%)$, Netherlands (7.60\%), Australia (3.40\%) and Belgium (3.20\%).

In comparing the international collaboration of other African countries with developed countries, a research done by Berthelemot, $\mathrm{N}$ et.al.(200I), found that the international collaboration was overriding in Biomedical Research, Biology, Earth and Space Science, and Physics. Institutions in the US were the principal collaborators followed closely by those in France. It should be noted that international collaboration is important in any research area, but the national collaboration between individual scientists as well as between institutions are vital for the development of science and scientific research within the country.

Recommendation

I. It follows naturally that further study should examine a different discipline, preferably social science, to determine whether there are differences between disciplines, and the patterns of those differences if any

2. A research can be done to see how much collaborative research is done between institutions within the country both among universities as well as between universities and other research institutions and companies which research in the same areas.

3. It is recommended that studies on collaboration dealing with inter-disciplinary research and collaboration be conducted both nationally and internationally.

4. A definite way of raising the standard of a country's economic status rests largely on the scientific research and discovery made in the country. It will be interesting to see if there are any research done between the well established universities and the historically disadvantaged universities as some of the second category of institutions have not done very much to raise their standards in research and publications.

\section{References}

Abrahamson, E. 199I. Managerial fad and fashion: the diffusion and rejection of innovations. Academy of Management Review, 16(3): 586-612.

Abrahamson, E. 1996. Managerial fashion. Academy of Management Review, 2 I (I): 254-285.

Abrahamson, E. \& Fairchild, G. 1999. Management fashion: lifecycles, triggers, and collective learning processes. Administrative Science Quarterly, 44, 708-740.

Berthelemot, N., Russell, Arvanitis, J., Waast, R \& Gaillard. 200 I. Science in Africa: An overview of mainstream scientific output. Proceedings of the $8^{\text {th }}$ international conference on scientometrics and informatics, 2 (4): 69-484.

D. de B. Beaver and Rosen, R. 1978. Studies in scientific collaboration: Part I - the professional origins of scientific coauthorship. Scientometrics, I, 65-84.

D.de B Beaver and Rosen, R. 1979. Studies in scientific collaboration: Part II - Scientific co-authorship, research productivity and visibility in the French scientific elite. I799- I830. Scientometrics, I, I33-I49.

D. de B. Beaver and Rosen, R. 1979. Studies in scientific collaboration: Part III-Professionalisation and the natural history of modern scientific co-authorship, scientometrics, I, 23I -245.

Godin, B., Robitaille, J., Côté, G. 200I. Profile of the Scientific Output of Agriculture and Agri-Food Canada. http:// www.ost.qc.ca/OSTE/pdf/rapports/200I/eRapport AAC.pdf

Gupta, B M. And Karisiddappa, C R. 1998. Collaboration in theoretical population -genetics specialty. Scientometrics, $42: 349$ 376.

Havemann, F. 200I. Collaboration behaviour of Berlin Life Science researchers in the last two decades of the twentieth century as reflected in the Science Citation Index. Scientometrics 52 (3) 435-443.

Havemann, F. 200 I. Collaboration and productivity of west-German Biomedical researchers 1980-84 and I4 years later. Talk at NISTADS International Workshop on Emerging Trends in Science \& Technology Indicators: Aspects of collaboration and The Second COLLNET Meeting. New Delhi, India, 20-25 February .

Hou, Haiyan and Kretschmer, Hildrun and Liu, Zeyuan. 2006. The Structure of Scientific Collaboration Networks in Scientometrics. In Proceedings International Workshop on Webometrics, Informetrics and Scientometrics \& Seventh COLLNET Meeting, Nancy (France).

SA Jnl Libs \& Info Sci 2008, 74(I) 
Jacobs, D and Ingwersen, P. 2000. A bibliometric study of the publication patterns in the sciences of South African scholars 1981-1996. Scientometrics, 47 (I) : 75-93.

Ingweren, P., and Jacobs, D. 2004. South African research in selected scientific areas: Status 198I-2000. Scientometrics, 59 (3) : 405-423.

Jacobs, D, 2006. Analysis of Scientific Research in selected institutions in South Africa: A bibliometric study. South African Journal of Libraries and Information Science , 72 (I) : 72-77

Ponzi,J.\& Michael, K. 2003. Knowledge management: another management fad, Retrieved January I, 2005 from: http:// pages.globetrotter.net/charro/HERMES9/ponzi koenig.htm.

Russell, M. 1995. The increasing role of international cooperation in science and technology research in Mexico. Scientometrics, 34 (I): 45-6I.

Seglen, P O, and Aksnes, D W. 2000. Scientific productivity and group size: A bibliometric analysis of Norwegian microbiological research. Scientometrics, 49: I 25 - I 43.

Subramanyam, K. 1983. Bibliometric studies of research collaboration: A review, Journal of Information Science, 6, 35.

D.J. de Solla Price, 1963. Little Science, Big Science... and beyond. New York: Columbia University Press.

Van Raan, A. 1998. The influence of international collaboration on the impact of research results. Scientometrics, 42(3): 423-428. 